\title{
CORRELAÇÃO DA SEGMENTAÇÃO ARTERIAL ESPLÊNICA COM A ANATOMIA DE SUPERFÍCIE
}

\author{
CORRELATION BETWEEN SPLENIC ARTERIAL SEGMENTATION AND SURFACE \\ ANATOMY
}

\author{
Ítalo Martins de Oliveira ${ }^{1}$; Karla Pinheiro Silveira ${ }^{2}$; Thiago Almeida Barroso ${ }^{2}$; \\ Soraya Alves Jacinto Oliveira²; Márcia Luna Teixeira ${ }^{3}$; Antônio Ribeiro da Silva Filho, TCBC-CE ${ }^{4}$
}

\begin{abstract}
RESUMO: Objetivo: A presente pesquisa objetivou aferir a localização, a quantidade e as dimensões dos segmentos arteriais do baço, bem como sua relação com a anatomia de superfície. Método: Foram utilizados 19 baços, procedentes do Departamento de

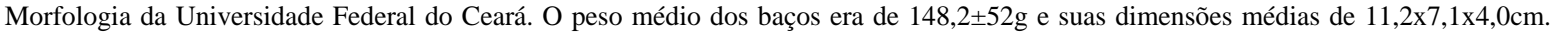
Foi injetada, nos ramos superior e inferior da artéria esplênica, resina sintética (resapol T-208) para preenchimento dos segmentos. Utilizando o método de corrosão, identificou-se a segmentação, diferenciando-a através de cores, analisando e comparando com a anatomia de superfície através de planimetria. Resultados: Os baços apresentavam em média 2,4 $\pm 0,61$ segmentos (2-4) e seus moldes representavam $70 \%$ da superfície diafragmática. Encontrou-se evidência de correlação entre os sulcos das chanfraduras esplênicas e a segmentação correspondente em 17 dos 19 baços 89,4\% 7,1\% (p< 0,05) que possuíam este relevo anatômico. Conclusão: A segmentação arterial esplênica pode estar diretamente relacionada com sua anatomia de superfície e ser utilizada como parâmetro na esplenectomia parcial e estudos de anatomia vascular esplênica (Rev. Col. Bras. Cir. 2008; 35(6): 406-410).
\end{abstract}

Descritores: Artéria esplênica /Anatomia \& histologia; Baço; Esplenectomia.

\section{INTRODUÇÃO}

As primeiras citações sobre baço humano se iniciaram desde Hipócrates e se intensificaram com Galeno (130 a 200 d.C.) que afirmou ser o baço um órgão misterioso com funções a serem descobertas. Somente em 1865, Cruveilhier descreveu a vascularização arterial esplênica, afirmando ser do tipo terminal e sem anastomose. ${ }^{1}$ Kyber et al descreveram o baço em humanos, cães, cavalos e coelhos como sendo dividido em diversos segmentos por septos fibrosos e que estes eram irrigados por sua artéria própria ${ }^{2}$. Dreyer e BudtzOlson descreveram que estes segmentos ainda eram drenados por sua veia própria através de venografia esplênica².

No Brasil, as primeiras esplenectomias parciais foram realizadas por Campos Cristo em $1959^{3,4}$, baseadas em estudos anatômicos de Zapalá, Neder e Di Dio sobre os segmentos arteriais do baço em 1958, estes utilizando moldes de acetato de vinil e angiogramas ${ }^{5}$. Contemporaneamente, Clausen et al. e posteriormente Gutierrez et al, em 1969, também demonstraram os segmentos esplênicos utilizando o método de injeção-corrosão de moldes arteriais ${ }^{2}$. Estudos realizados por Silva Filho e Aragão confirmaram a segmentação arterial esplênica como zonas independentes, utilizando para isso estudos anatômicos de penetração capilar ${ }^{1}$.
Este trabalho tem como objetivo de estudar a existência de correlação entre a segmentação arterial do baço e sua anatomia de superfície, visando a utilização deste conhecimento nas excisões cirúrgicas durante a esplenectomia parcial, bem como em novos estudos morfológicos da vascularização arterial esplênica.

\section{MÉTODO}

\section{Seleção e preparação do material anatômico}

Para a realização deste estudo foram utilizados 19 baços humanos frescos oriundos do Departamento de Morfologia da Faculdade de Medicina da Universidade Federal do Ceará. Todos foram provenientes de cadáveres de causa mortis violenta, encaminhados do Instituto de Medicina Legal do Estado do Ceará, sem alterações patológicas macroscópicas durante a autópsia ou sinais de ruptura do parênquima esplênico.

O hilo do baço foi dissecado cuidadosamente, individualizando a artéria esplênica e seus segmentos superior e inferior. Todos os baços foram pesados e medidos em seus comprimentos céfalo-caudal, ântero-posterior e víscero-diafragmático com paquímetro e balança digital.

\footnotetext{
1. Pós-Graduando do Programa de Doutorado em Cardiologia do Departamento de Cardiopneumologia da FM/USP, São Paulo - SP; Bolsista CNPqPIBIC no período da execução do projeto.

2. Médicos Graduados na Faculdade de Medicina da Universidade Federal do Ceará, Fortaleza - CE.

3. Residente de Dermatologia do Hospital Dona Libânia, Fortaleza, CE.

4, Professor Titular do Departamento de Morfologia da Faculdade de Medicina da Universidade Federal do Ceará, Fortaleza - CE.

Recebido em 30/06/2008

Aceito para publicação em 30/08/2008

Conflito de interesses: nenhum

Fonte de financiamento: nenhuma

Trabalho realizado no Departamento de Morfologia da Universidade Federal do Ceará - CE.
} 


\section{Injeção-Corrosão}

Deste modo, foi injetada resina (resapol T208) com diferentes cores em cada segmento da artéria esplênica de maneira seletiva e, na evidência de artéria polar, realizou-se o mesmo procedimento.

Foram realizadas fotos coloridas do baço em suas faces visceral e diafragmática a uma distância fixa de $30 \mathrm{~cm}$ para posterior análise, utilizando máquina fotográfica digital com três megapixel de definição.

$\mathrm{Na}$ etapa seguinte, prosseguiu-se a corrosão das peças, colocando os baços em solução de ácido clorídrico a $10 \%$ por 24 horas. Com isso, após lavagem cuidadosa do material com água corrente, obtiveram-se exclusivamente moldes da rede arterial, sendo novamente fotografados em suas faces visceral e diafragmática a 30 centímetros de distância e medidos os comprimentos céfalo-caudal e ântero-posterior. A definição das chanfraduras foi baseada nos sulcos definidos por elas e a as regiões segmentares arteriais nas zonas de encontro entre os moldes coloridos. Após isso, foram comparadas as imagens fotográficas dos baços e de seus segmentos arteriais correspondentes, sendo considerados como tais os segmentos sem diferença visual macroscópica entre as imagens fotográficas dos segmentos arteriais e os sulcos das chanfraduras através da análise computadorizada por translucência das imagens.

\section{Planimetria}

Para análise das relações e proporções entre os segmentos esplênicos, foi realizado estudo planimétrico. Para isto, foi utilizada projeção através de translucência com plano de pontos sobre a foto da peça a ser estudada, determinando a proporção relativa dos segmentos.
Para análise estatística dos resultados, foram utilizados o teste de Correlação de Pearson, o teste $t$ de Student pareado para amostras contínuas com distribuição normal e o Signal Test. As variáveis contínuas estão expostas em média \pm desvio padrão (valor mínimo-valor máximo) e as proporções em proporção \pm intervalo de confiança. Será considerado estatisticamente significante $\mathrm{o} p<0,05$.

O projeto de pesquisa foi aprovado no Comitê de Ética em Pesquisa do Hospital Universitário Walter Cantídio da Universidade Federal do Ceará, sob protocolo número 103/ 06, de acordo com as recomendações da Declaração de Helsinki, e da Resolução no 196/96 do Ministério da Saúde sobre pesquisa envolvendo seres humanos.

\section{RESULTADOS}

O peso médio dos baços foi de $148,2 \pm 72 \mathrm{~g}(87,3$ $306,0 \mathrm{~g})$. A distância céfalo-caudal média foi de $11,2 \pm 1,9 \mathrm{~cm}$; a distância ântero-posterior média foi de $7,1 \pm 1,4 \mathrm{~cm}$ e a distância antero-posterior média foi de $4,0 \pm 0,8 \mathrm{~cm}$. Referente aos moldes, a distância céfalo-caudal média foi de $9,05 \pm 1,2 \mathrm{~cm}$; a distância ântero-posterior média foi de $6,3 \pm 1,3 \mathrm{~cm}$. A superfície dos moldes apresentava, em média, $70 \%$ da área de superfície dos baços.

Ao analisar os resultados da planimetria através de translucência (Tabela 1), o segmento superior mostrou-se maior em relação ao inferior em 79ะ17,6\%, (Gráfico 1). Entretanto não foi demonstrada correlação entre o aumento de peso do baço e um aumento desproporcional entre seus segmentos (Gráfico 2), ou seja, o aumento normal do baço apresentou concomitante aumento proporcional de seus segmentos. Em

Tabela 1 - Dados referentes a planimetria dos moldes. Dados expressos em \%.

\begin{tabular}{|c|c|c|c|c|}
\hline \multicolumn{5}{|c|}{ Planimetria (\%) } \\
\hline \multirow[t]{2}{*}{ Peso Baço } & \multicolumn{2}{|c|}{ Segmentos Principais } & \multicolumn{2}{|c|}{ Segmentos Polares } \\
\hline & Superior & Inferior & Superior & Inferior \\
\hline 87,3 & 70 & 30 & & \\
\hline 89,5 & 61 & 39 & & \\
\hline 96,2 & 76 & 24 & & \\
\hline 102,0 & 83 & 17 & & \\
\hline 111,0 & 63 & 37 & & \\
\hline 114,1 & 53 & 47 & & \\
\hline 119,1 & 58 & 42 & & \\
\hline 127,0 & 61 & 39 & & \\
\hline 136,5 & 25 & 38 & 37 & \\
\hline 144,0 & 63 & 37 & & \\
\hline 150,5 & 62 & 38 & & \\
\hline 152,5 & 54 & 46 & & \\
\hline 157,6 & 67 & 33 & & \\
\hline 169,0 & 58 & 42 & & \\
\hline 171,2 & 52 & 39 & 9 & \\
\hline 180,6 & 50 & 20 & & 30 \\
\hline 194,5 & 50 & 41 & 9 & \\
\hline 207,7 & 50 & 12 & 3 & 6 \\
\hline 306,0 & 59 & 28 & 14 & \\
\hline
\end{tabular}




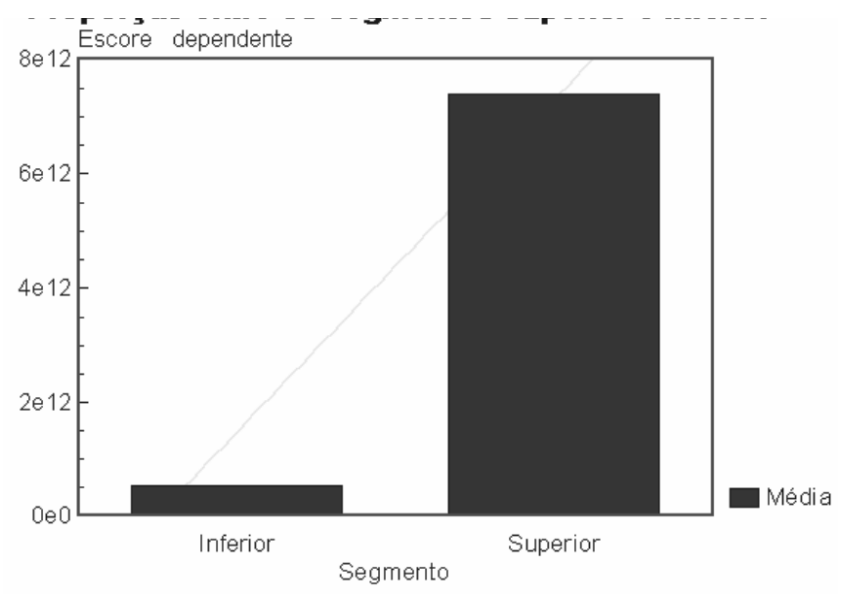

Gráfico 1 - Gráfico demonstrando maior proporção do segmento superior em relação ao inferior. $p=0,001$.

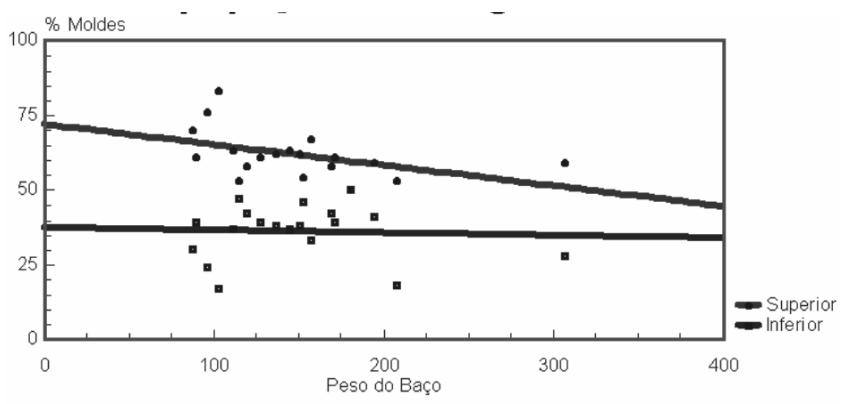

Gráfico 2 - Gráfico demonstrando a correlação entre os segmentos e o peso dos moldes. Coeficiente de correlação do segmento superior $r=0,446$ e do segmento inferior $r=0,499$.

cinco baços (26\%) foram encontrados segmentos polares superiores e em dois (10\%) segmentos polares inferiores, estes últimos proporcionalmente menores. Somente em um baço (5\%) houve coexistência de segmento polar superior e inferior. (Tabela 1).

Após a comparação das imagens fotográficas digitais dos baços e seus segmentos arteriais correspondentes, dos 19 baços estudados, $17(89,4 \% \pm 7,1 \%)$ foram considerados como apresentando correlação anatômica entre a anatomia de superfície dos sulcos das chanfraduras e os segmentos arteriais correspondentes obtidos através dos moldes. A análise estatística com o Signal Test obteve z =3,44 e p <0,05. (Figuras 1 e 2).

\section{DISCUSSÃO}

O baço adulto normal é ligeiramente côncavo, sólido, vermelho-escuro, mede cerca de $3 \times 8 \times 14 \mathrm{~cm}$, pesa entre $100 \mathrm{a}$ 175 gramas e, freqüentemente, apresenta chafraduras na sua borda anterior. No presente estudo não houve correlação entre o aumento do peso do baço e um aumento desproporcional entre seus segmentos ${ }^{1}$.

O baço é um dos principais locais para o início das respostas imunológicas e para a ativação de linfócitos $\mathrm{T}$ e linfócitos $\mathrm{B}^{6}$. A grande quantidade de células linfocitárias do baço, reunidas na polpa branca, constituem um tecido dinâmico encarregado do reconhecimento de antígenos e da produção de anticorpos ${ }^{3}$. A inter-relação entre linfócitos $\mathrm{T}$, linfócitos B e macrófagos é ampla no parênquima esplênico, sendo importante para a resposta imunológica normal, assim, considerando a importância funcional do baço é de se esperar que o comprometimento de sua atividade seja correlacionado com infecções e doenças auto-imunes ${ }^{7}$. Isto se aplica principalmente durante a atividade imunológica contra bactérias encapsuladas. Em 1919, Morris e Bullock relataram a importância imunológica do baço em infecções fulminantes pós esplenectomias totais em ratos, o mesmo sendo observado em esplenectomias totais em crianças por King \& Schumacker, $1952^{1}$. Na esplenectomia, as complicações tardias podem ocorrer por toda a vida do paciente. A sepse pós-esplenectomia é uma síndrome letal secundária à diminuição da resposta imunológica aos antígenos bacterianos ou à diminuição da capacidade de depurar as bactérias.

A partir de 1976, com Eisenberg, foram publicados vários trabalhos na literatura mundial a fim de demonstrar a importância imunológica do baço. Com isso, surgiram novas técnicas cirúrgicas para preservação esplênica, tais como esplenorrafia, esplenectomia parcial e o autoimplante do tecido esplênico no omento maior do estômago ${ }^{1,8}$.

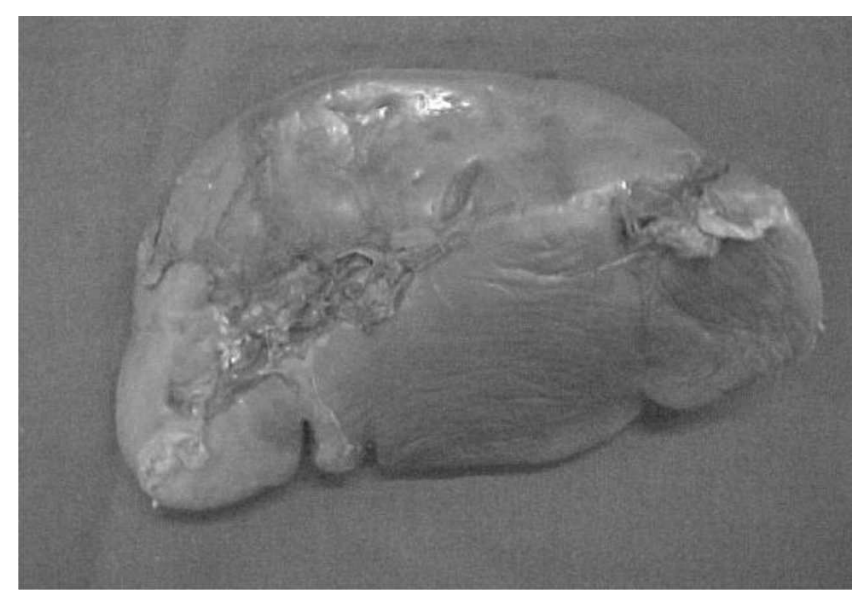

Figura 1 - Foto da face visceral esplênica, demonstrando 3 chanfraduras (setas).

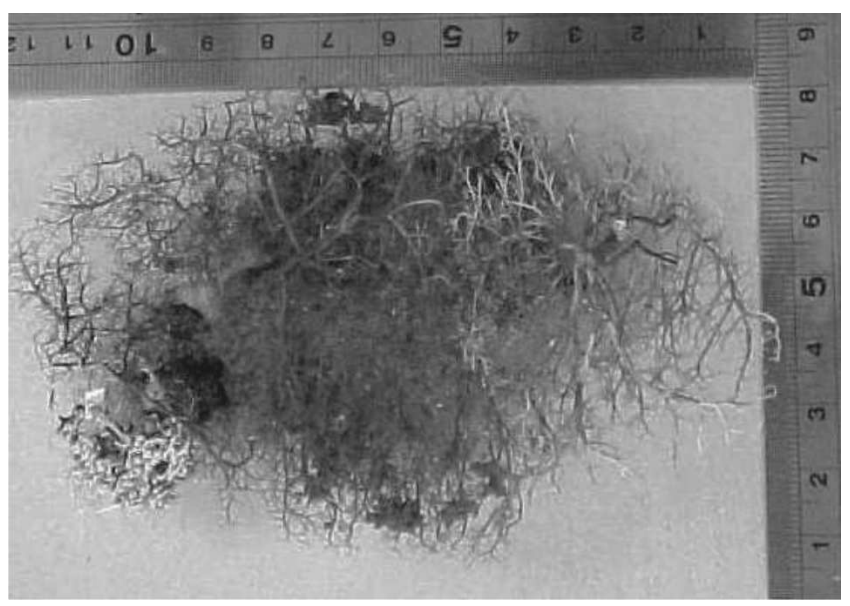

Figura 2 - Foto da face visceral do molde do baço da Figura 1, demonstrando a presença de 4 segmentos, sendo 2 polares. (setas) 
A esplenectomia parcial foi uma das técnicas desenvolvidas na tentativa de reduzir as complicações decorrentes da esplenectomia total. Sua aplicação se teve principalmente na cirurgia de trauma de baço, iatrogenia durante procedimentos cirúrgicos e até em hemagiomas esplênicos, em que ainda era possível se preservar parênquima esplênico ${ }^{5,9}$. Com isso, vários trabalhos foram realizados na tentativa de descrever mais detalhadamente a segmentação arterial esplênica, sendo confirmadas zonas independentes de drenagem e irrigação sanguínea, permitindo, assim, o aprimoramento da técnica cirúrgica. ${ }^{10,-13}$.

A artéria esplênica divide-se em duas artérias suprindo os segmentos superior e inferior, nomeando os seus ramos $^{1}$. O segmento superior é relativamente maior que o inferior, sendo este resultado demonstrado neste trabalho em $79 \%$ dos baços (Gráfico 1), p<0,001, corroborando com dados da literatura ${ }^{5}$. Podem existir as artérias polares superior e inferior, partindo diretamente da esplênica (Tipo I) ou das segmentares superior ou inferior (Tipo II) (Figura 3), chegando a serem encontrados de $30 \%$ a $60 \%$ dos $\operatorname{casos}^{5,11}$. Esta divisão determina segmentos vasculares bem definidos, sendo áreas anatomicamente distintas do tecido esplênico correndo da borda anterior para a posterior. Cada segmento tem seu próprio suprimento arterial e drenagem venosa e são separados uns dos outros por planos avasculares ${ }^{1,2}$. Neste trabalho, houve uma maior proporção de segmentos polares superiores (26\%) e foram encontrados segmentos polares inferiores em $10 \%$ dos casos. De modo inverso, Garcia-Porrero e Lemes descreveram que em 44,75\% dos 181 baços estudados tinham segmentos polares inferiores e somente $29,28 \%$ apresentavam o segmento superior. Neste mesmo estudo, a coexistência dos 2 segmentos polares ocorreu em 10,49\% dos baços ${ }^{12}$.

As chanfraduras esplênicas são resquícios embrionários das lobulações fetais ${ }^{13}$. Embora não foi encontrada descrição prévia entre correlação da anatomia de superfície e a segmentação arterial, no presente estudo demonstrou-se correlação entre as chanfraduras e a segmentação arterial esplênica, comprovando-se assim, correlação entre a independência arterial esplênica e sua anatomia de superfície ${ }^{14}$. Tal

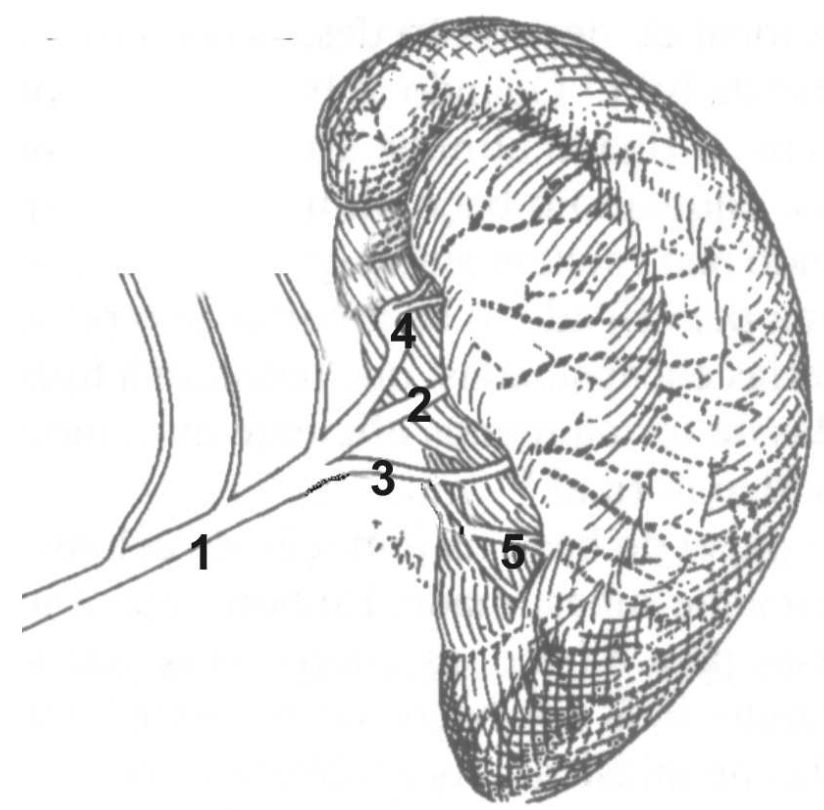

Figura 3 - Desenho esquemático demonstrando a estrutura arterial do baço. Artéria esplênica (1), artéria segmentar superior (2), artéria segmentar inferior (3), artéria polar superior (4) tipo I, artéria polar inferior (5), tipo II.

conhecimento permite maior segurança e precisão na abordagem cirúrgica durante a esplenectomia parcial, sendo outro dado importante na delimitação da excisão da porção esplênica afetada, principalmente nos casos de trauma e doenças lifoproliferativas ${ }^{15}$.

Com isso, o presente estudo concluiu que: o segmento superior é relativamente maior que o inferior, demonstrado neste trabalho em $79 \%$ dos baços; não houve correlação entre o aumento do peso do baço e um aumento desproporcional entre a relação dos seus segmentos; e observouse correlação entre os sulcos das chanfraduras na superfície do baço e a segmentação arterial esplênica, um importante dado anatômico com aplicação cirúrgica direta na esplenectomia parcial e nos estudos da segmentação arterial esplênica.

\begin{abstract}
Background: To determine segments' location, number and dimension as well as its relation to the spleen surface anatomy. Methods: Nineteen spleens were used, all provided by the Morphology Department of Federal University of Ceará. The spleen's average weight was $148.2 \pm 52 \mathrm{~g}$ and their average dimensions were $11.2 \times 7.1 \times 4.0 \mathrm{~cm}$. Synthetic resin (resapol T208) was injected into the superior and inferior spleen artery branches fulfilling the segments. After parenchyma corrosion, each segment was identified by a different color and analyzed by planimetry. Results: The spleens presented $2.4 \pm 0.61$ segments average (2-4), and its molds represent 70 percent of the diaphragmatic surface. Evidence of correlation between notch and the corresponding segment was found in 17 of the 19 samples $89.4 \% \pm 7.1 \%$ ( $p<0.05$ ). Conclusion: The splenic arterial segmentation may have a strict relation between its surface anatomies. It should be utilized as a parameter in partial splenectomy and other arterial segmentation studies.
\end{abstract}

Key words: Splenic artery/ anatomy \& histology; Spleen; Splenectomy.

\section{REFERÊNCIAS}

1. Silva Filho, AR. Vascularização do baço: estudo da independência e análise proporcional dos seus segmentos. [Dissertação]. São Paulo (SP): Escola Paulista de Medicina; 1989.
2. Gupta CD, Gupta SC, Arora AK, Singh PJ. Vascular segments in the spleen. J Anat, 1976;121(3):613-6.

3. Campos Christo M. Segmental resections of the spleen. Report on the first eight operated on patients. Hospital. 1962; 62:187204. 
4. Campos Christo M. Esplenectomias parciais sistematizadas réglées [dissertação]. Belo Horizonte (MG): Universidade Federal de Minas Gerais; 1961.

5. Christo, MC. O estado da arte da cirurgia do baço, no início do século XXI. Rev Col Bras Cir. 2005; 32(5):279-82.

6. Rozman C, Berga L, Feliu E. Baço como órgão filtrador. In: Jamra M, Lorenzi TF, editors. Baço: anatomia, fisiopatologia, clínica, cirurgia. Rio de Janeiro: MEDS; 1988. p. 219-43.

7. Jauregui E. Anatomy of the splenic artery. Rev Fac Cien Med Univ Nac Córdoba. 1999; 56(1): 21-41.

8. Ignjatovic D, Stimec B, Zivanovic V. The basis for segmental dearterialization: a post-mortem study. Surg Radiol Anat. 2005; 27(1):15-8. Epub 2004 Oct 29.

9. Petroianu A, Barndt CT, Alencar LF. Esplenectomia parcial para tratar hemangioma hepático. Rev Col Bras Cir, 2008;35(2):1325 .

10. Liu DL, Xia S, Xu W, Ye Q, Gao Y, Qian J. Anatomy of vasculature of 850 spleen specimens and its application in partial splectomy. Surgery. 1996;119(1):27-33

11. Redmond HP, Redmond JM, Rooney BP, Duignan JP, BouchierHayes DJ. Surgical anatomy of the human spleen. Br J Surg. 1989; 76(2):198-201

12. Cougard P, Trouilloud P, Morizot B, Gelle MC, Autissier JM. [Study of the vascular segmentation of the spleen]. Bull Assoc Anat (Nancy).1984; 68(200): 27-33.

13. Paulo DN, Paulo IC, Kalil M, Vargas PM, Suilva AL, Baptista JF, Guerra AJ. Subtotal splenectomy preserving the lower pole in rats: technical, morphological and functional aspects. Acta Cir Bras. 2006; 21(5):321-7.
14. Katritsis E, Parashos A, Papadopoulos N. Arterial segmentation of the human spleen by post-mortem angiograms and corrosioncasts. Angiology. 1982; 33(11):720-7.

15. García-Porrero JA, Lemes A. Arterial segmentation and subsegmentation in the human spleen. Acta Anat (Basel). 1988; 131(4):276-83.

16. Mandarim-Lacerda CA, Sampaio FJ, Passos MA. [Vascular segmentation of the spleen in the newborn infant. Anatomical support for partial resection]. J Chir (Paris). 1983; 120(8-9):4713.

17. Chadburn A. The spleen: anatomy and anatomical function. Semin Hematol. 2000; 37(1 Suppl 1):13-21.

18. Machálek 1 , Houserková D, Holibková A. A contribution to the vascular anatomy of the human spleen. Acta Univ Palacki Olanuc Fac Med. 1996; 140:11-5.

Como citar este artigo:

Oliveira IM, Silveira KP, Barroso TA, Oliveira SA, Teixeira ML, Silva Filho AR. Correlação da segmentação arterial esplênica com a anatomia de superfície. Rev Col Bras Cir. [periódico na Internet] 2008; 35(6). Disponível em URL: http://www.scielo.br/rcbc

Endereço para correspondência:

Ítalo Martins de Oliveira

Rua Guilherme Rocha, 1535 - Jacarecanga

60015-002 - Fortaleza - CE.

Telefone: +55 (85) 3091-6830

E-mail: italomartins@cardiol.br 